\title{
STRATEGIC MANAGEMENT OF THE FOURTH ASSET CLASS: REAL ESTATE AND THE FINANCIAL SERVICES SECTOR
}

\author{
Kannan N. ${ }^{1}$, Thangavel $\mathbf{N}^{2}$ \\ ${ }^{1}$ Research Scholar, Sathyabama University, Jeppiaar Nagar, Rajiv Gandhi Road, Chennai, India \\ 2Jeppiaar Engineering College, Chennai, India \\ E-mail : 'kannu74@yahoo.co.in
}

\begin{abstract}
Revenue Growth. More Revenue Growth. And More Revenue Growth This is the mantra you can hear chanted through the halls of financial services firms all around the world today. It is particularly important to this segment of the economy since share prices have climbed $91 \%$ in the last 4 years. Most organizations would probably answer "product innovation". However, if you examine this closely, the reality is that even product innovation does not ensure competitive advantage. Over $\$ 11 \mathrm{~b}$ is spent by financial institutions on this a year, but even a new kind of offering gives a company less than a 3 month lead over its competitors. New products also often bring with them increased complexity, an increase in operating costs and unsatisfied customers This paper focuses on the Problem C's: Complexity, Consolidation, Compliance and Costs and the Solution: Process Improvement in Real Estate with IWMS and also giving Strategies for Process Improvement followed by the conclusion given.
\end{abstract}

Key words: Real Estate, Financial Services, Insurance

\section{INTRODUCTION}

The Relentless Drive for Revenue Growth

Revenue Growth. More Revenue Growth. And More Revenue Growth This is the mantra you can hear chanted through the halls of financial services firms all around the world today. It is particularly important to this segment of the economy since share prices have climbed $91 \%$ in the last 4 years. So the million dollar question is where in the future is this incredible revenue growth going to come from? Most organizations would probably answer "product innovation". However, if you examine this closely, the reality is that even product innovation does not ensure competitive advantage. Over $\$ 11 \mathrm{~b}$ is spent by financial institutions on this a year, but even a new kind of offering gives a company less than a 3 month lead over its competitors. New products also often bring with them increased complexity, an increase in operating costs and unsatisfied customers. And the failure rate is high, 60$80 \%$. There are other obstacles to organic growth today including saturation of products in markets which have become mature, increased sophistication of the customer base, new competitive threats emerging from retailers (i.e. Walmart and Target) and insurers, increased costs due to requirements for complying with regulations (not only SOX, but Basel II and the International Financial Reporting Standard) and the costs associated with the high churn rate of customers moving from one bank to another.

What some consultancy firms have proposed is that profitability for financial service organizations will come from looking within their own companies. "The game will be to steal market share and share of the wallet by relearning the growth habit through innovative practices." Two of these 'practices' are process innovation and automation of these new processes. By innovating internal operations, greater efficiencies are achieved, the work that is done is more effective and capital can be redeployed to focus on the core business. This paper addresses one often overlooked area for process innovation and technology deployment, corporate real estate (CRE). In a press release announcing Dr. Glenn Mueller's appointment as investment strategist for Dividend Capital, he made the statement that in addition to cash, stocks and bonds, real estate was coming to be viewed as the 'fourth asset class.' We believe that not all organizations recognize this, and a discussion of the value of real estate holdings is often not heard in the $C$ suite offices until the CFO is trying to raise capital and tells the VP of CRE to sell off real assets (particularly in an up market) or some traumatic event occurs. This could be a natural disaster, like Hurricane Katrina which shut down operations for an extended time and destroyed property or following a merger or acquisition when the financial markets were expecting massively reduced cost of operations and it did not happen. The time is ripe to recognize the value real estate can bring with new process innovations and system implementations, like Integrated Workplace Management Systems (IWMS). This paper describes new strategies for an organization to pull increased efficiencies out of internal operations of its real assetbase.

\section{THE PROBLEM C's: Complexity, Consolidation, Compliance and Costs}

\section{Complexity}

The interior world of the financial services firm is an extremely complex environment. It is a world full of companies who have joined together through 
consolidation opportunities with different work practices, cultures and disparate and redundant systems trying to sing from the same songbook. It is a world where outsourcing is on the agenda or will be for all financial institutions, and not only for transaction-based back room operations and call centers, but higher valued analytical studies as well. It is a world which bet on the retail branch becoming obsolete and now realizing that not only did that not happen, but the local branch is now more important to revenue growth than ever. It is a world peopled with not very loyal and extremely restless customers, with only half of them staying with the same branch and only half of those remaining who will recommend that bank to any of their friends or colleagues. And it is a world that is already full of thousands of financial products, often one more confusing than the next. A UK market study counted 29,000 different products on the market at any one time...how's that for complexity!

Wharton has published a report on the increasing complexity in services and describes how banks and other financial institutions are often closer to their customer base than most companies, but this can be a problem. "In fact, they could actually be smothering both themselves and their customers with dispensable or outdated offerings, made worse by overburdened internal processes that ultimately hurt the essential elements of survival-customer service and satisfaction." And because complexity does not jump up as a problem on a financial statement, there is often a lack of perspective can have a profound impact on the costs of operations.

\section{Consolidation}

Consolidation is not new to financial services as there has been much merger and acquisition activity for the last decade. But mergers and acquisitions have increased as companies try to find a balance between more risky segments of their portfolio, like investment banking, with more stable offerings, like retail banking. In fact, today is being dubbed the 'retail renaissance.'Savvy financial executives are learning new dance steps, not from their competition, but from the ubiquitous coffee houses and hamburger franchises who understand how to sell to the $21^{\text {st }}$ century customer. Therefore, instead of distancing themselves from their customers as they did with the advent of the ATM machine, they are turning the staid old bank branch where we went to perform some financial transaction into a financial "center". This ensures all of their innovative products are understood and accepted by the market anytime any day that the customer wants to have a more in-depth discussion of their financial needs. Some of these retail "stores" have become so successful that they are recording more foot traffic than the local hamburger joint with the golden arches down the street.

\section{Compliance}

The finance function of a bank is being entirely restructured due to the growing requirements from the regulatory agencies. Not only do they have to comply with Sarbanes-Oxley in the US and tighten financial controls, upgrade their management of risk and ensure greater transparency. In addition, the global players (and even some of the regional and national banks) are preparing for Basel II and the International Financial Reporting Standards (IFRS).

Basel II is the International Convergence of Capital Measurement and Capital Standards. It is the outcome of the Basel Committee on Banking Supervision's work over recent years to better align the regulatory capital measures with the risk profile of a bank based on market, credit and operational risks. IFRS requires compliance with IAS 39 which is constantly being amended and in turn makes implementation more difficult. And to make matters even more difficult, IAS and Basel II do not always agree, further complicating compliance.

\section{Costs}

"Revenue growth is the primary driver of shareholder value and the \#1 challenge for financial service companies around the world. Yet, this time around, the industry's growth objectives are tempered by a continuous focus on cost containment."

A discussion of real estate is often not even on the table until some traumatic event occurs, like bad financial transactions which cost the company millions of dollars in unnecessary expenses of following a merger or acquisition when the financial markets were expecting massively reduced cost of operations which did not happen. We believe real estate needs to be recognized now, not as a problem but as an enabler. One financial institution in Australia even views real estate as this fourth asset class and revenue generator as it invests in shopping centers, toll roads, airports and even broadcast towers.

\section{THE SOLUTION : Process Improvement in Real Estate with IWMS}

In order to respond to all of the above drivers, real estate organizations have to investigate new ways of adapting to the changing requirements of their customers (the business units), as well as continuing the quest to reduce costs. As mentioned previously, one area that has been repeatedly overlooked is most commercial real estate; the land, buildings and equipment on the buildings (ATMs) and in the buildings (i.e. furniture, computers, 
trading floor technology) that an organization leases and/or owns. There is now a new attitude toward these assets today as the value of real estate alone has risen substantially and can no longer be ignored. Nor can the value of the knowledge about these assets not be paid attention to, which is about to walk out the door with baby boomer retirees if no formal system is in place to capture this valuable information.

This paper addresses how executives in the financial services industry should apply their same level of fiduciary analysis to this fourth asset class that they apply to their cash, stocks and bonds. There are enterprise technological tools available today to give executive management, along with their real estate and asset management teams, the information to make informed decisions as they determine where, when and how their capital should be deployed. It is time to explore new strategies and technologies, like the Manhattan IWMS solution, which can raise the financial intelligence of the real estate function to help create a highly productive workplace for the financial services industry.

An Integrated Workplace Management System has been described by Mike Bell, Gartner Group, as an "enterprise-level software solutions that integrate four key components of functionality: project management; real estate portfolio and lease management; space management (moves, adds and changes [MAC]); and maintenance management. The software operates from a single database, and it offers workflow tools, executive dashboards, and predefined and customized reporting capabilities. Most suite applications will interoperate with other enterprise applications, such as enterprise resource planning (ERP), supply chain management (SCM) and human capital management (HCM), via Web services technology."

In fact, Manhattan Software is in the leadership position of the Gartner Magic Quadrant for this market. In order to plan for the use of this system, we present in this paper two strategic approaches that involve the use of the IWMS solution will first be described and then a definition of the metrics which can be reported on using this solution will be provided which can be utilized to measure the success of these strategies for the business.

\section{STRATEGIES FOR PROCESS IMPROVEMENT}

IWMS solutions support critical real estate strategies for reduction in operating, occupancy and capital costs while at the same time, improving the efficiency and effectiveness of the management of real estate and assets from an investment point of view. Solutions, like Manhattan, are utilized by corporate occupiers, investors, consultants and service providers in real estate to standardize data and processes leading to more accurate and timely financial and business metrics. Three real estate strategies discussed in this paper are asset management, location analysis and business intelligence.

\section{Strategy 1: Asset Management}

Asset Management deals with the financial and operational aspects of providing and maintaining resources for the organization. Corporate Real Estate professionals are now called upon to have an even stronger financial skill set than they currently have. The goal of asset management is to:

II Increase the performance of the portfolio while minimizing the operational risk;

I. Faster benefits from consolidation;

פु Easier and more accurate compliance;

I. Reduced operating and capital costs.

For the large financial services organizations, asset owners have been changing at such a fast rate, it is difficult for the acquiring company to adjust the business processes and systems of the acquisition quickly enough to not affect the performance of the entire company. By implementing an IWMS with a strong financial core, such as Manhattan, previously manual and cumbersome processes can be integrated easily and both current and historical data on real estate and assets can be made available for immediate decision making.

\section{Increased Performance of the Asset Portfolio in a Complex Environment}

In terms of office real estate, most of corporate real estate assets are currently underperforming by as much as $50 \%$, as space remains underutilized on a daily basis in our mobile world of work. There have been reports that typical middle managers in organizations are not in their offices $30-40 \%$ of the time (on average). This can cost an organization millions of dollars in operating expenses it does not need to spend. Manhattan allows a CRE executive to get a complete profile of the entire real estate portfolio, including information on which assets are owned or leased, which spaces are occupied and which are vacant, where space is utilized to full capacity and where it is underutilized. For retail branches, metrics can be reported on revenues per square foot and benchmarked amongst different locations. It also provides a chart of accounts to calculate the operating cost of each of the buildings so that each organizational unit can be charged appropriately. All costs associated with providing and 
maintaining the workplace and their associated assets are tracked, not only for accountability, but also to benchmark those costs with other properties and real estate portfolios of other companies.

The IWMS can also cross functional lines, and include the tracking and managing of all the asset data for an organization (office buildings, retail branches, call centers, training centers, grounds, parking complexes, ), furniture and equipment and information technology assets (ATMs, desktops, laptops, printers). In many large organizations there are hundreds of systems created to track these assets separately and an IWMS can be used to support an enterprise-wide asset portfolio strategy. With Manhattan, an organization now has the data to measure the critical financial data associated with all of these assets for the business units. Examples of Key Performance Indicators (KPIs) which can be tracked include measuring the profitability of customer-facing resources (retail establishments), defining the Return On Net Assets (RONA) and/or Return On Assets (ROA) per asset, and comparing the revenue/employee/location versus the cost/employee/location.

In the following sections, we define some of the benefits of managing the asset portfolio with an IWMS which includes reduction in costs and risks and increased compliance and transparency.

\section{Reduced Operational Risk in a Complex Environment}

Strategic risk has been defined as "an unexpected event or set of conditions that significantly reduces the ability of managers to implement their intended business strategy." A key risk which can have a large financial impact on the performance of an organization is operational risk. This is most significant when it impacts the core business activities of a company. Having a fully implemented IWMS can be critical to both continuing operations or returning to business following an emergency or disaster.

By conducting periodic condition assessments of buildings and entering the data on the status of building components into Manhattan, remediation can be proactively identified and a capital plan can be prepared with the required projects prioritized. This not only prevents costly emergency repairs (which can represent $20-60 \%$ in savings), but can prevent lost productivity due to downtime. A roof leaking over a critical operation in a call center can cause the company expensive loss and downtime which can be as much as a structural failure in building housing financial trading activities. Unanticipated disasters do happen (as we have seen occur in 2005 with Hurricane Katrina) and with the implementation of a system like Manhattan (with offsite redundancy) can ensure an organization is back and doing business as quickly as possible.

\section{Increased Compliance}

Financial services organizations have the not only Sarbanes-Oxley compliance to deal with, but the large global banks have to comply with Basel II and the International Financial Reporting Standards, mentioned earlier. SOX was created to foster transparency and accountability in corporate business processes and accounting practices and restore confidence in the public markets. As Deloitte Consulting has pointed out: "If you leverage your SOX compliance efforts to include a hard look at business processes and systems, you will find complexities that, if eliminated, can cut costs, sometimes dramatically. Therefore every executive in the financial services industry will want to be assured that a CRE executive can answer the following questions:

1. Can CRE provide an accurate, up-to-date and consistent summary of the company's real estate portfolio? How much is owned and leased? Where is each asset located? What commitments have been made in the future? What is it costing?

2. Is there a rigorous, well-documented process in place that tracks acquisitions and dispositions across the portfolio?

3. Are transactions completed in different geographical locations subject to the same definitions, assumptions and metrics and carefully documented?

4. Can the company document its comprehensive real estate expenditures, including costs managed by vendors, consultants or business partners?

5. Are accounting standards for excess space in the portfolio-and potential impairment costs-rigorously documented and consistently followed?

6. If the company uses synthetic leases to finance any part of its occupancy, are these structures consistent with the compliance provisions for these "special purpose entities?"

7. Increase cash flow through componentized depreciation by being able to segment a building by subsystems which each have their own depreciation schedule.

Many of Manhattan clients have gained savings of tens of millions of dollars year after year by not only taking advantage of the improvements and savings listed above, but by simply better managing space and the movement 
of the employees throughout the space. Valuable space has been found to be unused or underused (in one case by as much as $30 \%$ of the portfolio) and the information about this potentially revenue producing space (amount, function, asset value, occupancy) was non-existent or spread across multiple systems and multiple service provider organizations. By implementing Manhattan IWMS and a business intelligence system, static data about space is transformed into "actionable intelligence, enabling decisions that significantly reduce vacancy rates, decrease current costs and support planning that will keep costs down over time."

\section{Strategy 2: Asset Location Analysis}

For both CRE executives' internal customers and for the organization's external customers, location strategies will remain critical to decision making. While much of the way we work today may be virtual, place continues to play a critical role in most business unit strategies whether it is a sales/marketing organization (where are existing customers and markets, as well as future ones located?), operations (where do we have existing call centers, and workforce groupings and where do future ones need to be located?), R\&D (where are the best locations to find the researchers we need?), finance (where can I locate/consolidate facilities to satisfy the business units at the lowest operating costs?) and retail (where is the most potentially profitable location for ATMs in X area?). Some banks are even investing in commercial real estate near their corporate headquarters buildings. Bank of America is building a Ritz Carlton next to its home office building in Charlotte and half of its occupancy will be their own traveling employees. PNC intends to build an office/hotel/condo project in the same city with $30 \%$ of the costs being picked up by the State and City.

By integrating Manhattan with a Geographical Information System (GIS), not only can the existing locations be graphically represented on a map, but other data pulled from the database can be associated with each location (costs, org unit, performance, personnel per city, building, floor, space, revenue etc.). GIS can also provide valuable demographic and logistics data for strategic decision making. A portal can be created which can be customized to workers' requirements.

Whatever databases, documents, drawings or maps they may need can be easily retrieved from this one screen. Questions can be answered such as: Which locations do you keep and which do you dispose of after a merger/acquisition? For those locations you do keep, what costs will have to be incurred to bring them up to the quality or performance level of the acquiring company? All of these questions can be considered when data is collected on the inventory of the new properties and input into Manhattan. Then condition assessment data can be associated with each of the buildings or environmental assessments attached to land records and viewed on a map.

One west coast energy company conducted a physical and functional assessment for all of its service centers. They married this data on the condition of their internal and external buildings and structures as well as plant, equipment and mechanical/electrical equipment with their inventory and maintenance information on each center in their IWMS. This allowed them to prioritize their capital expenditures, determine which centers had the potential for re-use (i.e., regional office building into a call center) and which buildings and land could be sold into the marketplace.

After implementing a program for asset management and integrating IWMS with graphical data, the next step is integration with business intelligence (BI) tool to determine how well assets are performing for your organization.

\section{Strategy 3: Business Intelligence}

Mike Napier, head of corporate real estate for Shell, has discussed how important it is to understand the business issues and drivers intimately and have real estate become part of the business planning cycle. When he was asked about the corporate real estate organization in 2010, Mike mused, "The successful organization of the future is going to be heavily tech based, and clearly one of our priorities continues to be our database and just having complete knowledge of the portfolio together to make the right decisions. You can't make decisions without the information. And then how that information is used in terms of sharing across networks and being able to use different databases and tools to analyze in different ways."

Manhattan's IWMS is the solution (interfaced to other databases such as SAP, AutoCAD and HR) that Mike uses for the management of Shell's real estate portfolio which consists of 65,000 properties scattered in 140 countries around the globe. He now has the information to be able sense what the business units will need to perform and can respond with the appropriate asset strategy. He also can use a BI tool to mine the data and monitor the performance of these assets at all locations. Another critical component is the integration of Manhattan to the SAP financial database. Most companies implementing an IWMS must integrate in some way with their corporate ERP solution and abide by the strict rules of the corporate finance team. The flexibility 
of Manhattan's interface options enables companies to fit into that structure and provide the level of detail required by CRE executives.

Only organizations, like Mike's, who have the data in their IWMS, can effectively demonstrate how real estate can have a positive influence on business-related performance measures by analyzing the metrics such as these listed below:

Operational Metrics: Improving the Efficiency and Affordability of Operations: By being able to capture total cost of occupancy (TCO) of the buildings associated with each of the business units, a KPI of TCO/revenue ratio $(E / R)$ can result in increased performance. By measuring the actual costs of CRE, inefficiencies can be driven out of the TCO. Metrics include total occupancy cost per square foot and per person, square feet per person, net present cost of surplus space and surplus space to total space. Keith Perske of Sun Microsystems has observed, "If an increase in revenue causes an associated increase in expense, better management of facility resources that leverage existing investments can create a wider profit spread with less ongoing expenditures. A 4\% reduction in operating costs can result in the same profit as a $25 \%$ increase in sales because we're able to shift the savings from RE actions to places in the company where it can be highly leveraged." John Suyker of Johnson Controls, in a recent review of internal infrastructure, described how a 10\% occupancy cost saving resulted in a $28 \%$ EBIT increase.

\section{Productivity Metrics: Improving the Productivity of People and Place:}

By creating metrics that measure revenue/person (gross), EBIT/person (net) and comparing these to revenue/sf (particularly with retail space), the productivity of the employees can be measured by location and benchmarked with others both within the company and outside. In addition, metrics which determine how efficiently an organization is making use of its real estate include identifying total occupancy costs and doing a comparison with the company's turnover and operating costs.

\section{Value Metrics: Improving Return on Assets:}

These metrics define how the real estate portfolio is affecting the value drivers in the organization. They include determining what the CRE cost of capital is and comparing it to the company's cost of capital, as well as calculating the TCO as a percentage of the free cash flow the organization generates. Another metric would be to capitalize the value of the CRE's debt and equity and measure it against the company's enterprise value. The
ROA metrics aid in setting key targets for measuring performance. The metrics include cost/occupant, cost/capacity, cost/sf, and cost/sales, goods and administration (SG\&A) to determine how high their return on assets are, and then they compare the results with other similar oil and gas companies.

By investing in the implementation of IWMS systems and processes, corporate real estate management can be assured not only that controls are in place for more efficient and effective standardized business processes, but there is better financial reporting. This should ensure the decisions that are made on the real estate and asset portfolio are more transparent and are done so in light of the business strategies.

\section{CASE STUDY}

\section{A Large Global Financial Institution Implements Manhattan's IWMS}

Last year a large, global financial institution selected the Intelligent Workplace Management Solution (IWMS) from Manhattan Software as the business solution to manage one of the most extensive corporate real estate portfolios in the world.

This bank serves individual consumers, small businesses and large corporations and institutions with a full range of banking, investing, asset management and other financial and risk management products and services. The Corporate Workplace group of this organization is responsible for the management of office space, operations/data centers, retail banking centers and ATMs which comprise one of the largest corporate portfolios with over 85 million square feet of Bank owned and leased space worldwide. Managing a portfolio of this size, and accommodating the rapid growth of the Bank, which is constantly acquiring other banks, required the Corporate Workplace group to implement an enterprisewide Integrated Workplace Management System.

Manhattan has a fully contained financial and real estate management suite of applications. With these modules, Finance and Portfolio teams are able to easily manage at the general ledger account level from a true real estate perspective. Industry standard cost coding conventions can replace current codes which allowed for better analysis, benchmarking and reporting. Manhattan is being interfaced to the Bank's business intelligence environment which enables intuitive web based queries and custom reporting. Now critical KPIs can be compared across the portfolio, whether it means measuring the performance of two different properties or two different 
regions within a country.

\section{CONCLUSION}

Leveraging an IWMS like Manhattan increases the cost savings for real estate and infrastructure, and gives a real estate organization the ability to adapt to the complex and changing environment of the oil and gas industries. In one case study following a merger, Manhattan succeeded in helping improve the financial position of CRE and asset management leadership resulting in consolidation, disposition and efficiency projects saving millions of dollars. The implementation of a Manhattan Solution has followed business process improvement projects and supported these by embedding these new processes in their workflow tools and making the information available to anyone who needs it in the organization or external service providers through a web-based portal.

Before using Manhattan, many of the cost saving opportunities were identified by throwing darts, blindfolded! Maybe some 'low hanging fruit' would fall out. With the IWMS tool, it is like having a shot gun standing 8 feet from the target. Manhattan gives you the power to make the right financial decisions at the right time and at the right cost no matter how complex the world gets for financial institutions

\section{REFERENCES}

[1] Deloitte Consulting, "Glittering Prize: How Financial Institutions can drive Growth thru Process and Service Innovation." 2005, p. 5.

[2] Ibid, p. 2. The Wharton School, University of Pennsylvania, Knowledge@Wharton, "Taming Complexity in Services: Stay Close to Your Customer (But Not Too Close)", knowledge.wharton.upenn.edu.

[3] Deloitte Consulting, "Global Banking Industry Outlook 2005", p. 3.

[4] "London Calling: Macquarie Bank," The Economist, October 13,2005.

[5] RONA=Return on Net Assets and ROA=Return on Assets This list of questions is taken from "SOX,CRE and the CFO: How the SarbanesOxley Act Impacts Corporate Real Estate and the Chief Financial Officer," by Michael A. Billing, Vice President of Strategic Consulting for Jones Lang

[6] Ed Lubieniecki and John D'Angelo, "CRE Business Intelligence: A New Tool for Strategic Effectiveness." 2004. www.realfoundations.com

[7] "Shell International's Mike Napier: We're Business People First, Real Estate People Second." By Tim Venable.

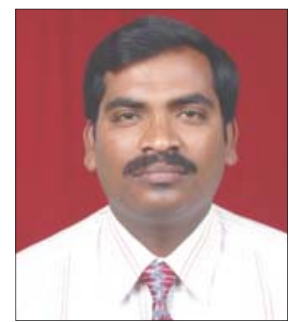
Corporate Real Estate LEADER

Mr. N. Kannan is a Research Scholar at Sathyabama University, Chennai and Senior Lecturer at St.Mary's School of Management Studies, Chennai. His area of specialization is Finance and

Entrepreneurship. He has over ten years of teaching experience and has guided about one hundred MBA project $s$ a $n \mathrm{~d}$

$f$ i $\vee \mathrm{e}$ M. Phil. theses. 